\title{
Esencia y hecho en Zubiri ¿En qué sentido puede entenderse la filosofia de Zubiri como una fenomenología? 1
}

\section{(Fact and essence in Zubiri. How can we conceive Zubiri's philosophy as phenomenology?)}

\author{
Óscar BARROSO FERNÁNDEZ
}

Recibido: 27 de marzo de 2012

Aceptado: 15 de enero de 2013

\section{Resumen}

Frente a la interpretación canónica de Zubiri, que ve en el camino que va de Sobre la esencia (1962) a Inteligencia sentiente (1980-1983) el proyecto de una depuración fenomenológica de la filosofía -en el sentido de una noología-, en el presente trabajo se mostrará la continuidad entre ambas obras, a través del análisis de las nociones de "hecho" y "esencia". Desde aquí concluiremos que si tiene sentido entender la filosofía de Zubiri como una fenomenología, ésta ya no puede ser caracterizada como un saber absoluto e infundado.

Palabras clave: Zubiri, Husserl, fenomenología, esencia, hecho, inteligencia sentiente.

\footnotetext{
${ }^{1}$ Una primera versión de este trabajo fue presentada y discutida en el Seminario de Investigación de la Fundación Xavier Zubiri de Madrid, en su sesión del 11 de febrero de 2011. Constituyó la tercera sesión dedicada a una polémica abierta a propósito de qué es "aprehensión" en Zubiri. Las intervenciones anteriores acerca de esta problemática estuvieron a cargo de Diego Gracia ("El acto de aprehensión", 12 de noviembre de 2010) y Víctor Manuel Tirado ("Logos humano y accesibilidad de lo real. Vueltas a las fuentes prístinas de la experiencia", 3 de diciembre de 2010). Hay grabación de las ponencias en la Fundación X. Zubiri. También pueden ser consultadas, solicitando acceso, en la web de la Fundación: http://www.zubiri.net/?page_id=43.

Quisiera agradecer a los evaluadores anónimos de este escrito las recomendaciones hechas. Gracias a ellas, el trabajo ha mejorado sensiblemente respecto a su primera versión.
} 


\begin{abstract}
This paper dissents from the canonical interpretation of Zubiri's philosophy, which tends to conceive the way from On essence (1962) to Sentient Intelligence (1980 - 1983) as a project of phenomenological refinement of philosophy as noology. On the contrary, the continuity of both works is shown in the analysis of notions of "fact" and "essence". This is the basis to conclude that it makes sense to conceive Zubiri's philosophy as phenomenology, as long as it's not characterized as an absolute and unfounded knowledge.
\end{abstract}

Keywords: Zubiri, Husserl, phenomenology, essence, fact, sentient intelligence.

\title{
1. Introducción
}

A partir de la publicación de Inteligencia sentiente, entre los zubiristas se creó un consenso amplio respecto al carácter fenomenológico de su quehacer. Muchas de las ideas que aparecían en la trilogía, habían sido ya abordadas en Sobre la esencia y los cursos que Zubiri venía impartiendo desde finales de los años cuarenta; pero frente al talante profundamente metafísico de aquellos trabajos, ahora el enfoque era nítidamente fenomenológico. La depuración fenomenológica de la filosofía de Zubiri se llevó a cabo a lo largo de los años setenta.

Dicho esto, lo cierto es que, pasados más de treinta años desde que Zubiri comenzara la publicación de su trilogía, todavía quedan muchas lagunas respecto a cómo ha de entenderse su filosofía; sobre si la noología es realmente una forma de fenomenología o sí, más bien, va más allá de ésta².

En el presente trabajo pretendo arrojar luz sobre esta cuestión a través del estudio del sentido que Zubiri dio a las nociones de "hecho" y "esencia" a lo largo de su obra. Con ello intentaré demostrar que la supuesta depuración fenomenológica -noológica- que Zubiri hizo de su filosofía en el tránsito de Sobre la esencia a Inteligencia sentiente, no constituye una superación - de lo metafísico hacia lo noológico-, sino un cambio de perspectiva que nunca renunció al talante metafísico de Sobre la esencia.

\footnotetext{
2 En los últimos años, distintos especialistas (Rodríguez 2009, Serrano 2010, García-Baró 2012) han mostrado, además, que la caracterización que el zubirismo ha hecho de la fenomenología, no ha sido capaz, salvo contadas excepciones, de ir más allá de la interpretación que el propio Zubiri hizo la filosofía de Husserl. Algo que, por lo demás, no afecta sólo al zubirismo, sino, en general, a su recepción en España. Serrano (2010, pp. 481-482) afirma, con acierto, que el Husserl de la cultura española no especializada en fenomenología es el que Zubiri transmitió en Cinco lecciones de filosofía.
} 


\section{Hechos y esencias en la interpretación zubiriana de Husserl}

En su Memoria de Licenciatura, a propósito de la fenomenología husserliana, Zubiri afirma que el objeto, correlato de un acto elemental de conocimiento, puede ser "bien esencial (especies ideales), o bien un hecho (cosas reales)" (Zubiri 1999, p. 58).

Estos hechos son, por un lado, los dados en la concepción natural del mundo, y, por otro, los que tratan las ciencias. Pero junto a estos dos usos de la noción de "hecho" aparece otro esencial al propio método husserliano: los "hechos fenomenológicos". Estos hechos surgen, precisamente, sólo tras la reducción de los otros dos tipos de hechos. Son hechos originarios, previos a toda construcción científica y al modo natural en que el mundo nos es dado. Los hechos fenomenológicos son "hechos puros" y a su contenido se le denomina "fenómeno". Se aprehenden a través de la intuición fenomenológica. Por ello son dados previamente a toda actividad inductiva, deductiva o interpretativa. Se trata de hechos no-sensibles y a priori.

Para Zubiri, este concepto de "hecho" es equivalente al de "esencia" en la fenomenología de Husserl y Scheler ${ }^{3}$. El hecho fenomenológico es tal porque se ofrece a la descripción fenomenológica como algo inmediato. Por ello, el contenido de los hechos fenomenológicos, los fenómenos, se alcanzan descriptivamente. Hemos arribado a lo que, a juicio del joven Zubiri, constituye la esencia del método fenomenológico: descripción de hechos-fenómenos puros - contrapuestos a los fenómenos entendidos como realidades existentes- $\mathrm{y}$ dados sin necesidad de establecer previamente una teoría del conocimiento o una psicología. Así entendido, el fenómeno es el objeto en su dimensión presente inmediatamente a la conciencia. La fenomenología, en tanto que descripción o análisis intuitivo de fenómenos, es una ciencia inmediata y absoluta. En sus intuiciones no cabe el error. La intuición fenomenológica es absoluta, aunque la mediación lingüística que supone la descripción de fenómenos pueda conducir a errores, que, en todo caso, pueden ser depurados.

\footnotetext{
3 La interpretación de la fenomenología por parte de Zubiri está más próxima de la sensibilidad scheleriana, para quien efectivamente la reducción fenomenológica era equivalente al conocimiento de esencias, que del espíritu propiamente husserliano. Tanto García-Baró (2012, pp. 179-180) como Serrano (2010, pp. 488 y ss.), han visto que aquí en Zubiri hay un defecto en la comprensión de la reducción fenomenológica, consistente en la identificación del fenómeno de la intuición con la esencia, es decir, con el ser virtual ideal. En esta interpretación, la reducción fenomenológica se identifica con la reducción eidética. En sus años de juventud, Zubiri, que había llegado a la fenomenología desde la Escolástica, vio en esta especie de platonismo reformado, objetivista, una filosofía que permitiría presentar batalla contra el subjetivismo y el idealismo. Pero eso significa que una vez que Zubiri recuse el esencialismo, no estará criticando el proceder husserliano, sino, más bien, la interpretación defectuosa que él había elaborado. En defensa de Zubiri habría que decir que el Husserl que tiene en mente por estos años es el de las Investigaciones lógicas. Fue muy crítico con Ideas, en tanto que constituía un retorno al idealismo trascendental. De tal forma que podemos entender que la identificación de fenómeno y esencia en Zubiri es el resultado del rechazo de la reducción fenomenológica (trascendental).
} 
Desde esta interpretación de la fenomenología, es comprensible que Zubiri la conciba como una ciencia descriptiva previa a toda ciencia explicativa. La fenomenología, como ciencia descriptiva de fenómenos, se constituye en filosofía primera. Toda explicación, ya sea vital, científica o metafísica, ha de reposar en la ciencia fenomenológica, ciencia absoluta e inefable.

Ante una ciencia así concebida, ¿por qué retorna en Sobre la esencia a una posición metafísica? Zubiri entenderá que aquel conocimiento absoluto se había conseguido a costa de algo que ahora va a rechazar: la separación tajante de los ámbitos de esencialidad y de realidad, y, en consecuencia, entender la esencia en términos de sentido. Desde esta perspectiva, la necesidad natural es sólo necesidad de hecho. Todo lo real es individual y todo lo individual es contingente. Por ello las leyes naturales son leyes de hecho y comparten el carácter de contingencia de los hechos mismos. En cambio, una ley esencial ha de expresar una necesidad absoluta al no depender de hechos, de la realidad fáctica.

Para determinar el ser absoluto de esta esencia, bastará - dado que la esencia es el término de un saber absoluto- con lograr tal saber. Dado que la realidad define el ámbito de la contingencia, este saber no puede ser otro que aquel que ponga entre paréntesis el carácter mismo de realidad: "tomar el término de aprehendido tan sólo en cuanto aprehendido, y el acto de aprehensión tan sólo en cuanto un darse cuenta" (Zubiri 1962, p. 25). Descubrimos que estos términos no pueden darse el uno sin el otro, al perder ambos su carácter de realidad. Estamos ante la intencionalidad:

lo aprehendido en cuanto tal no es sino lo intentum, el correlato intencional de aquel 'de', el término intencional 'hacia' el que la conciencia se dirige, es decir, el 'sentido' (Sinn) de esta intención (Zubiri 1962, p. 25).

Así, el sentido es irreductible al hecho, ya que no es objeto real sino puro "eidos". El saber absoluto, no sometido a las condiciones empíricas, es un saber sobre la esencia entendida como unidad eidética de sentido. La conciencia sería esencia de las esencias, por ser el soporte esencial de todas ellas.

Lo importante para Zubiri es que esencia y realidad aparecen como dos orbes separados, siendo la esencia fundante de la realidad:

la esencia como sentido no sólo es independiente de la realidad y fundante de ella, sino que además se basta a sí misma. Es el único ente tal que no necesita de ningún otro para ser lo que es: puro sentido. Su ser es, pues, absoluto (1962, p. 27).

\section{Más allá del sentido y de la contraposición entre hechos y esencias}

En el prólogo a la traducción inglesa de Naturaleza. Historia. Dios, Zubiri sitúa en el año 1932 el tránsito de su etapa husserliana a la heideggeriana. A partir de este 
momento se mantiene una "idea de fenomenología", en tanto que filosofía capaz de "abrir el libre espacio del filosofar frente a toda servidumbre psicológica o científica" (Zubiri 1944, p. 14), pero se supera el marco concreto de la fenomenología husserliana, es decir, la fenomenología en tanto que eidética y trascendental. Zubiri considera ahora que "la cosas no son meras objetividades, sino cosas dotadas de una propia estructura entitativa" (1944, p. 14). No se trata de una filosofía que "va a las cosas mismas", sino de una filosofía hecha "desde las cosas" (Zubiri 2002, p. 214). Así lo ve Zubiri ya a la altura de 1932, en el artículo "Filosofía y metafísica", y considera que tal proceder no constituye un abandono de la fenomenología, sino, más bien un madurar de la misma (2002, pp. 179-214).

¿Qué entiende, pues, Zubiri por fenomenología? Más que una filosofía concreta, una forma de filosofar que ha ganado su objeto propio, que no se conforma con tener un carácter genitivo, es decir, con ser un tipo de saber dependiente esencialmente de otros saberes. A juicio de Zubiri, la fenomenología, como idea de la filosofía, y no como el concreto proceder de Husserl, sigue siendo la filosofía en la que se inscribe Heidegger, y en él se apoyará ahora para partir de las cosas mismas y no de las objetividades de la conciencia. Aunque en estos años ya es posible encontrar incoativamente lo que será su filosofía de madurez: un rastrear tras el ser la realidad, un paso de la ontología a la metafísica.

Para Zubiri, aunque Heidegger ha superado la conciencia husserliana, no ha logrado ir más allá de la esfera del sentido como ámbito propio de la fenomenología $^{4}$. La pretensión de Zubiri consistirá precisamente en buscar la realidad tras el sentido. Una realidad que es inteligida sentientemente como "de suyo", poder y fuerza.

Por otra parte, en Heidegger, el mundo de las esencias, sencillamente, ha desaparecido de escena. Aunque Zubiri coincide con Heidegger en la pretensión de situarse en la facticidad, rechaza que esta tenga que ser incompatible con el ámbito de la esencialidad. Zubiri busca lo real y su ámbito esencial y no, como Heidegger, el ser y su esfera de sentido.

A juicio de Zubiri, las notas esenciales no dependen de nuestro modo de considerar la cosa, sino que constituyen "lo que" es una cosa real; un momento estructural físico de la cosa misma: "no pueden en manera alguna faltar a una cosa real sin que ésta deje en estricto rigor de ser lo que es" (1962, p. 17). La esencia es, entonces, algo necesario en la cosa misma.

\footnotetext{
${ }^{4} \mathrm{Ha}$ de quedar claro que me refiero a la lectura que Zubiri hace de Heidegger y no al pensar de Heidegger en sí mismo. Aunque Zubiri leyó todo lo que llegó a sus manos escrito por Heidegger, en su obra sólo se mide con el Heidegger ontológico. En los últimos años han aparecido trabajos excelentes que han intentado mostrar la proximidad de la filosofía de Zubiri al pensar esencial de Heidegger tras la Kehre. Son especialmente recomendables los de González (2004) y Espinoza (2004).
} 
Pero si facticidad y esencialidad no constituyen mundos diferenciados, para superar la distancia entre ellas es preciso que Zubiri vuelva a la interpretación que había desarrollado en sus trabajos de juventud de la filosofía de Husserl.

Zubiri afirma que la reflexión husserliana sobre la esencia es insostenible tanto en sus supuestos como en la idea de esencia que maneja. En cuanto a los supuestos, Husserl se equivoca en la manera de enfocar la cuestión, porque lo que busca a toda costa son evidencias absolutas - de decir, que valen de un modo necesario e incondicionado- y no las cosas mismas. Con ello abandona su lema fundamental "a las cosas mismas" por la búsqueda de un saber absoluto. Ha lanzado el problema de la esencia por el lado del saber, y al final no nos dirá lo que es la esencia, sino sólo el modo de conciencia en que presuntamente es dada; un modo absoluto de conciencia:

Al desviarse de las cosas y dirigirse a la conciencia en beneficio de un saber absoluto, Husserl ha perdido, en el enfoque mismo de la cuestión, lo esencial de la realidad. Logrará a lo sumo un tipo de 'pensar esencial', pero jamás la esencia de las cosas (1962, p. 28).

Para superar esta noción de esencia, Zubiri afirmará que los actos intelectivos no consisten formalmente en "ser-intención-de", sino en actualización de su objeto. Y recíprocamente, el ser del objeto no consiste en "ser-relativo-a", sino en estar meramente actualizado. Así que el ser objeto intencional de la conciencia no excluye el ser realidad, "sino que además consiste en remitir formalmente a lo que el objeto es independientemente de la conciencia y de su sentido" (1962, p. 29). Remisión que es física, como física es la propia actualización. Pero entonces la esencia ya no puede ser entendida como sentido. El sentido será sólo un carácter de la esencia como momento intencional de la conciencia; previamente a tal momento la inteligencia remite físicamente a algo previo al sentido: "Las cosas no 'remiten' a la esencia como a un sentido regulador a priori de su realidad" (1962, p. 30). Las esencias están realizadas en las cosas mismas. Y por ello, la realidad no es puro hecho contingente, sino que envuelve como momento suyo la necesidad esencial. De nuevo, "la realidad de hecho y la esencia no se contraponen en la forma que Husserl pretende" (1962, p. 30), sino que la esencia es algo intrínseco y propio de la realidad de hecho.

Por fin, esencialidad y facticidad unidas:

no son dos regiones de entes, dos clases de 'cosas', sino tan sólo dos momentos de toda realidad. La esencialidad concierne al momento estructural de lo real, y no al sentido objetivo de mí saber absoluto. Al separar esos dos momentos - esencialidad y facticidad- y sustantivarlos a beneficio de dos tipos de saber -saber absoluto y saber empírico- Husserl ha descoyuntado la realidad, y la realidad se le ha ido para siempre de las manos (1962, p. 32). 
Husserl tenía que buscar la manera de "ir a las cosas mismas" porque no había partido realmente de ellas, sino de un pretendido saber absoluto. No es de extrañar que se haya pensado que Zubiri estaba radicalizando el método fenomenológico: filosofía "desde las cosas mismas", más allá de que tal filosofía tenga o no un carácter absoluto.

En su análisis de la esencia, Zubiri tiene que superar un grave problema: aunque renunciemos a concebir la esencia como algo separado de la realidad, ¿cómo entender su necesidad incardinada en los hechos? ¿Hay hechos necesarios? Para responder a esta pregunta nos ofrece en Sobre la esencia una clasificación de los hechos.

\section{Noción de "hecho" en Sobre la esencia. Lo factual como necesidad real.}

A juicio de Zubiri, las notas o propiedades que constituyen una esencia, no dependen de otras notas sino sólo de sí mismas -del sistema que configuran-: son infundadas o últimas. Y en tanto que no dependen de otras notas, lo más que podemos decir de ellas es que "solamente son" $(1962$, p. 196). Al aclarar qué es lo que significa "solamente ser", Zubiri define dos sentidos de "hecho".

La primera forma en que podemos entender el "solamente ser" es la "precisiva": "se toma algo en y por sí mismo prescindiendo de si tiene o no fundamento" (1962, p. 196). Esta precisión puede ser lógica, pero también "una vivencia inmediata en la que la realidad es aprehendida solamente como algo que es, esto es, una especie de realidad en bruto" (1962, p. 196). La realidad aparece así como término de "mera constatación". A la realidad así aprehendida se le puede llamar "hecho", no porque sea meramente hecho, sino tan sólo como un modo de considerar la realidad. En realidad, en esta perspectiva no podemos hablar de notas esenciales o inesenciales. Sencillamente, todas son iguales. Se puede observar que si en Zubiri hay un sentido fenomenológico del "hecho", ha de aparecer en esta forma precisiva de "solamente ser".

Si intentamos superar el punto de vista de la mera constatación propio del análisis precisivo, sumergiéndonos en la condición real misma de la realidad, para inteligir la cosa en su fundamento, descubrimos que la cosa está constituida por tres tipos de notas. En primer lugar aparecen las notas propiamente contingentes -aquellas que son de una forma pero podrían perfectamente haber sido de otra-. En segundo lugar aparecen notas necesarias en el sentido de estar determinadas forzosamente por la índole misma de la conexión de las cosas. Por último, encontramos otras notas que no son ni contingentes ni necesarias -en el sentido mencionado-, sino que su condición real aparece como "solamente ser realidad". Aquí, nos dice Zubiri, 
el adverbio 'solamente' no designa mi modo de considerar las cosas, sino que bajo sus apariencias negativas expresa la positiva condición metafísica de la realidad de la esencia. Si se quiere seguir hablando de 'ser' diremos que no es la 'indiferencia' sino justamente al revés, la 'suficiencia' misma del ser en el orden constitucional (1962, p. 197).

El sistema de notas esencial no podría ser de otra manera en la cosa misma sin que esta dejara de ser lo que es, por eso no es algo meramente contingente. Tal sistema, además, no es necesario en el sentido conexivo mencionado, porque, sencillamente, es un sistema que descansa sobre sí mismo. Es en este sentido que "solamente es realidad". Desde luego, hablando desde una perspectiva absoluta, trascendente, en referencia a un supuesto fundamento último de las cosas, todo podría ser considerado contingente respecto de Dios, toda la creación participa homogéneamente de la contingencia. Pero tomando el mundo en y por sí mismo, es decir, manteniéndonos en una perspectiva intramundana, las realidades dejan de tener dicha condición homogénea en su respectividad mutua.

Rota dicha homogeneidad, junto a la contingencia y la necesidad -determinada por la conexión de las cosas-, aparece la suficiencia propia de las notas esenciales. Suficiencia significa aquí "ab-soluto", en el sentido etimológico de la palabra. Las notas esenciales son "ab-solutas" en tanto que están "sueltas-de" todas las demás (1962, p. 207). El "realmente ser" apunta a que las notas esenciales no son ni contingentes ni necesarias; son absolutas, tienen suficiencia constitutiva, son "en y por si mismas formalmente suficientes" para constituir un sistema sustantivo.

Zubiri había criticado a Husserl por hipotecar el análisis de la realidad con vistas a alcanzar un saber absoluto y necesario. Pero el filósofo vasco nos hace ver que lo absoluto, desde el punto de vista de la realidad y no del saber, no es lo necesario, sino lo "autosuficiente" (1962, p. 208). La esencia no es ni fáctica ni necesaria, es, dice Zubiri, "factual":

Lo factual conviene con lo fáctico en 'no' estar fundado en necesidad ninguna. Pero se distingue abismáticamente de lo fáctico en que éste, por muy contingente que sea, se halla fundado, justo contingentemente, en la realidad, mientras que lo factual no está fundado en nada intramundano ni necesaria ni contingentemente. Lo absoluto es lo que es y nada más; es simpliciter realidad y nada más. Si se quiere seguir utilizando la palabra 'hecho' habría que decir, por paradójico, aquello pudiera parecer, que lo esencial es 'hecho absoluto', no simple hecho, sino puro factum (1962, p. 209).

Por cierto. Mientras analizábamos este segundo sentido del "solamente ser" con vista a aclarar en qué consiste "esencia", nos ha aparecido la segunda noción de "hecho". Al intentar inteligir la cosa en su fundamento, las notas que aparecen como meramente contingentes constituyen "realidades de hecho". 


\section{Noología y fenomenología: discusión en torno a la presunta distancia entre Sobre la esencia e Inteligencia sentiente}

¿Coincide la noción de "hecho" en Inteligencia sentiente con algunas de las nociones de Sobre la esencia? Obviamente, la descripción de hechos en Inteligencia sentiente sólo podría referirse a la forma precisiva de la evidencia inmediata de Sobre la esencia, porque la distinción entre las notas que constituyen realidades de hecho y las notas esenciales exige una investigación experiencial de la realidad, es decir, exige situarse en el nivel de la razón. Esto significa que si a lo que Zubiri analiza se le puede denominar hecho fenomenológico, hay que aceptar que no se trata de un análisis esencial, tal como el que, según Zubiri, pretendía Husserl.

Pero, ¿cómo casar el que Zubiri niegue la esencialidad al nivel del mero análisis de hechos con la afirmación continúa en Inteligencia sentiente de que la aprehensión primordial de realidad constituye la esencia misma de la intelección humana?

Para aclarar esto es necesario recurrir de nuevo a Sobre la esencia, donde nos hace ver que la esencia puede entenderse de tres maneras distintas: En primer lugar, esencia es lo que responde a la pregunta de 'qué' es algo, su quid. El qué de algo son todas sus notas en tanto que constituyen una unidad interna. Todas las notas son de la cosa. Si careciera de unidad no tendríamos una cosa, sino varias:

el 'qué' significa todo aquello que de hecho es la cosa real en cuestión con la totalidad de notas que posee (...) Así es como toda cosa nos está presente en su aprehensión primera y es en ella término de la función deíctica, esto es, de mera indicación nominal: es 'esto' (1962, p. 16).

En segundo lugar, el 'qué' puede tener una acepción más restringida aunque ya no en los términos de una "aprehensión primera", sino, nos dice Zubiri, de una "aprehensión simple", que a su vez ha de ser distinguida de la "simple aprehensión". Al comparar una cosa real con otras, esta cosa presenta notas que rápidamente cobran una función caracterizadora o distintiva suya. El 'qué' así entendido no responde a la pregunta de un quid deíctico, sino a la pregunta de un quid denominativo:

Este quid no abarca la totalidad de las notas que la cosa comprende hic et nunc, sino tan sólo el conjunto de aquellas notas que posee como propiedad distintiva suya y que no le son indiferentes, sino que constituyen su característica mismidad (1962, p. 17).

Por último, se puede observar que el límite riguroso entre aquellas notas que caracterizan la mismidad de una cosa real y aquellas otras que le son indiferentes o accesorias en el respecto anterior es muy vago. La búsqueda de las notas realmente esenciales, que no pueden faltar en rigor para que la cosa deje de ser lo que es, 
nos lleva al concepto estricto de esencia. Pero no pensemos que los otros dos conceptos de esencia son accesorios a este último. En realidad, ni el quid denominativo sería posible sin la mera constatación, ni la búsqueda de la esencia rigurosa sería posible sin el quid denominativo:

En este tercer y estrictísimo sentido, la conceptuación de la esencia presupone la aprehensión del 'qué' de algo en el segundo sentido. Precisamente porque sabemos ya lo que es la cosa (Pedro, perro, hombre, etc.), es por lo que nos vemos forzados por la cosa misma a buscar el concepto de su estricta esencia. Esto es, sabemos qué es la cosa, pero no comprendemos conceptivamente en qué está su esencia. Pero como sabemos ya (en el segundo sentido) lo que la cosa es, sabemos también a dónde tenemos que dirigir nuestra mirada mental para asegurarnos de la rectitud de cada uno de nuestros ulteriores pasos intelectivos. El 'qué' en el segundo sentido, es pues, lo que forzosamente nos plantea el problema de la esencia en sentido estricto, y además lo que hace posible su tratamiento $(1962$, p. 18).

Esto significa que aunque al nivel del mero análisis no aparecen las esencias en un sentido estricto -el uso de la noción de "esencia" en este ámbito es muy laxo-, tal análisis adquiere una relevancia fundamental a la hora de ir hacia dicha esencia. La exploración de qué sea la esencia entitativa sólo es posible fundada en el análisis previo de la realidad. El análisis de lo inmediatamente dado es un análisis fundamental respecto a toda marchar allende lo dado.

Entre los especialistas en Zubiri, es habitualmente mantenida la tesis de que la distinción entre aprehensión primordial de realidad, logos y razón como tres niveles intelectivos constituye un logro que sólo alcanzaría Zubiri en Inteligencia sentiente $^{5}$. Creo que esta clasificación en las formas de entender la esencia deben advertirnos de la continuidad que se observa entre Sobre la esencia e Inteligencia sentiente. Considero, así, que estas tres nociones de esencia corresponden a los tres niveles de la inteligencia sentiente.

La afirmación de que la aprehensión primordial de realidad constituye la esencia de la inteligencia sentiente está hecha desde el segundo sentido de esencia. Tal sentido surge en el ámbito del logos, que no es más que análisis de hechos. Los hechos son dados, pero el análisis mismo no es dado. Toda Inteligencia sentiente es, obviamente, un análisis desde el logos del hecho intelectivo.

\footnotetext{
5 Esta tesis se sostiene junto a la idea de que en ese trayecto Zubiri depuró fenomenológicamente su filosofía con el establecimiento de una filosofía primera de carácter noológico. A la base de esta interpretación encontramos importantes obras de Gracia (1986) y Pintor-Ramos (1994). A ellas debemos el inestimable mérito de haber situado a Zubiri plenamente en el debate filosófico contemporáneo, frente a ciertas tendencias a recluirlo en una forma más de neoescolástica. Aunque tal lectura ha contado desde sus inicios con inteligentes respuestas (cf. Martínez Castro (2004) y Bañón (1999)).
} 
Esta continuidad entre Sobre la esencia e Inteligencia sentiente, ha sido puesta en duda por Diego Gracia en su ponencia presentada en el Seminario de Investigación de la Fundación Zubiri el 12 de noviembre de 2010.

Partamos, como el propio Gracia hacía, de lo que Zubiri nos dice al respecto en la página 353 de Sobre la esencia. Allí cree que es un error

considerar que la predicación misma es la primera y primaria función de afirmar lo real qua real, de suerte que los nombres serían tan sólo 'simples aprehensiones', esto es, meras designaciones de conceptos, totalmente ajenos a la afirmación. Pero esto es inexacto. La forma primaria de aprehensión afirmativa de lo real es la forma nominal. Y esto no sólo porque, como veremos más tarde, hay frases nominales, sino también porque el simple nombre desempeña a veces la función de designar afirmativamente la realidad de algo, sin la intervención del verbo ser. Antes de la división del logos en simple aprehensión y afirmación predicativa hay un logos previo, que es, indiferencialmente, lo que he solido llamar una 'aprehensión simple', que es, a la vez y simplemente, denominación afirmativa de lo real. Es un logos ante-predicativo, el 'logos nominal'. Por tanto, no puede identificarse el logos con el logos predicativo (1962, p. 353).

Recordemos que en Inteligencia y Logos, llamará "retracción" (1982, p. 84) al movimiento por el cual tomamos distancia de la cosa aprehendida para inteligirla desde otras. Dirá además que el producto de la retracción es la "simple aprehensión": una proposición de lo que la cosa dada en aprehensión primordial de realidad sería "en realidad". Zubiri afirma que hay tres formas de simple aprehensión: percepto, ficto y concepto. Recordemos también que en Inteligencia y logos hace referencia a tres formas de afirmación (1982, pp. 151-171): posicional, preposicional y predicativa.

Para entender lo que quiere decirnos en Sobre la esencia, es necesario aclarar en qué consiste la afirmación posicional. Un ejemplo: la exclamación “¡Fuego!” si abro la ventana y veo efectivamente fuego. Lo aprehendido en aprehensión primordial de realidad está aprehendido en todas sus notas:

Esto ya aprehendido, lo aprehendo con aprehensión primordial, como algo real, en toda su riqueza y variedad de notas, pero sin inteligir lo que es 'en realidad'. Inteligirlo como fuego, lluvia, etc., es justo la afirmación propia del juicio, a saber, lo que es en realidad lo aprehendido. Estos nombres, como meros nombres, son simples aprehensiones (perceptos, fictos o conceptos). Pero en connotación afirmativa expresan que lo simplemente aprehendido se realiza en lo que he aprehendido primordialmente, y es lo que éste es en realidad (1982, p. 152).

Creo que a partir de aquí podemos concluir que la diferencia entre aprehensión simple y simple aprehensión en Sobre la esencia, apunta a que aunque es cierto que por ejemplo la palabra "fuego" puede actuar como una simple aprehensión, en concreto, como un concepto, también puede indicar que estamos ante una afirmación 
de tipo posicional y, por lo tanto, ante-proposicional y ante-predicativa. Para indicar este último caso es para lo que Zubiri utiliza la expresión "aprehensión simple".

En cambio, a juicio de Gracia, lo que Zubiri llama "aprehensión simple" en Sobre la esencia equivale a la "aprehensión primordial de realidad" en Inteligencia sentiente. Y considera que antes de la división del logos en "simple aprehensión" y afirmación predicativa, hay un logos previo, equivalente a la "aprehensión simple" y que consiste en denominación afirmativa de lo real. Esto es lo que en Inteligencia y logos coincidirá con la "afirmación posicional". Desde aquí Gracia mantiene que en Inteligencia sentiente se corrige el planteamiento, de tal forma que no se puede hacer coincidir la aprehensión primordial de realidad con la aprehensión simple, ya que en la primera, al ser compacta, no hay ninguna afirmación. Zubiri estaría descubriendo un nivel más radical que el del logos.

Para mantener esta tesis, Gracia se apoya en una serie de conferencias impartidas por Zubiri en junio de 1976 en las que el campo aparecía al principio del análisis. El comienzo fenomenológico de Zubiri era claro, pero donde Husserl decía "campo de conciencia", Zubiri se refería al "campo de realidad". Lo que ahora preocupaba a Zubiri era ver cómo se fija la atención en este campo. Y en tal perspectiva parece no haber atisbos de una aprehensión anterior a la del logos, a la "aprehensión simple". En mi lectura, en cambio, previamente a la aprehensión simple, Zubiri consideró en Sobre la esencia una "aprehensión primera" previa al logos, pero insistamos un poco más en la lectura de Gracia.

Este construye su argumentación en dos pasos. En primer lugar, considera, como ya he señalado, que en las conferencias citadas de 1976, no hay diferencia entre aprehensión primordial de realidad y logos. A mi juicio, tal afirmación choca con el hecho de que en el curso de 1966 El hombre y la verdad, Zubiri distingue entre "nuda intelección" y "comprensión", residiendo toda dualidad en el ámbito de la comprensión, lo que indica que la nuda intelección apunta ya perfectamente al modo de la aprehensión primordial de realidad. Y en ese mismo año, en Sobre la realidad aparece esta misma idea bajo la denominación de "aprehensión de realidad", ya por entonces acto elemental, exclusivo y radical de la inteligencia (Zubiri 2001, pp. 30-31).

El segundo paso de Gracia consiste en suponer que si la aprehensión primordial de realidad es efectivamente compacta, en ella no tiene cabida hablar del campo como tal. Obviamente, en tal perspectiva lo fundamental es aclarar el "como tal". Si con ello se quiere indicar que no aparece el campo en tanto que objeto de análisis del logos y, por tanto, de una forma distanciada, la afirmación de Gracia resulta a todas luces obvia. Pero no creo que signifique, como da a entender Gracia, que no aparezca el campo de realidad. En realidad, Gracia parece querer decirnos que en la aprehensión primordial de realidad los contenidos quedan marginados a favor de la mera formalidad. 
Tales tesis chocan con el análisis que Zubiri hace en su trilogía. Efectivamente, en la trilogía Zubiri sitúa claramente el campo en la aprehensión primordial de realidad. El siguiente pasaje es nítido al respecto:

si aprehendemos las cosas en el campo de realidad podemos a su vez aprehenderlas de dos maneras. Una, como cosas que están incluidas en el campo: es inteligir las cosas como campales. Pero podemos también aprehender las cosas en función del campo en el que están incluidas: es inteligirlas campalmente. Aprehender la cosa campal es propio de la aprehensión primordial de realidad. Aprehender la cosa campalmente es lo propio del $\log$ os $(1982$, p. 20).

Es como si Gracia renunciara a esta distinción entre "aprehender campal" y "aprehender campalmente", y, con ello, descartara cualquier inclusión de contenidos concretos en aprehensión primordial de realidad. Con lo que la distinción que Zubiri estableció en Sobre la esencia entre "quid deíctico" y "quid denominativo" desaparece en Inteligencia sentiente. Por mi parte creo que la distinción entre "lo campal aprehendido" y "lo campalmente aprehendido", apunta a la diferencia entre lo aprehendido deícticamente y lo aprehendido denominativamente. Gracia no ignora las pruebas al respecto. Así se hace cargo de las páginas de Inteligencia y realidad en que Zubiri aclara el concepto de "fijación". Aquí Zubiri afirma que en aprehensión primordial de realidad "me fijo solamente en aquello que aprehendo en y por sí mismo" (1980, p. 260). Tal fijación es "atención", me centro en lo aprehendido, y "precisión", lo que no está aprehendido como centro queda al margen de la aprehensión. Lo que no está aprehendido como centro, queda marginado, aprehendido imprecisamente, frente a lo preciso, que es aquello a lo que "precisivamente estoy apuntando" (1980, p. 261). Gracia interpreta estas líneas de Zubiri entendiendo que aquello en que se centra la atención en la aprehensión primordial de realidad es en el momento de formalidad y no en los contenidos. Por mi parte, considero que tal atención se corresponde con lo que en Sobre esencia era la aprehensión deíctica y que, por lo tanto, se refiere a contenidos.

A mi juicio, respecto al planteamiento de Gracia, la pregunta interesante es ipor qué este empeño por distanciar la aprehensión primordial de realidad de los contenidos concretos? Creo que no obedece más que una nostalgia del absoluto fenomenológico (cf. D. Gracia, 2008, pp. 41-43). En su interpretación, todo contenido es construido, lo que significa que de haber contenidos en la aprehensión primordial de realidad, esta misma aparecería como construida. Dejarlos fuera, en cambio, permite salvar lo absoluto de la aprehensión de realidad en su trascendentalidad. Esta intención resulta nítida si atendemos a la ponencia que el 3 de diciembre de 2010 presentó Víctor Tirado en el mismo seminario y a la discusión con Gracia al respecto.

Tirado interpreta la "atención" referida en las páginas citadas de Inteligencia y realidad, como algo pre-lógico: lo aprehendido inmediatamente queda centrado, el 
campo aquí aparece en cambio imprecisamente aprehendido. Al respecto, Gracia respondió que tal atención y su carácter deíctico es ya afirmación posicional, con lo que en ella estamos ya sumergidos en el logos.

Repito que a mi juicio es posible distinguir entre el momento deíctico de la aprehensión, que aparece ya en aprehensión primordial de realidad, y su momento afirmativo, propio del logos. Para el momento deíctico es suficiente con la atenciónfijación; para la afirmación es necesaria la toma de distancia del logos, desrealización, y la libre construcción. En la aprehensión deíctica no se precisa libertad: esta atención radical no es libre, sino simplemente el resultado de que cuando siento, siento algo concreto. De nuevo tropezamos con el empeño de Gracia por salvar el carácter absoluto de la aprehensión primordial de realidad. Y para ello resulta necesario dejar algo al margen de la creatividad y la constructividad del logos y la razón; ya que la formalidad nos viene dada, mientras que el contenido, si implica atención deíctica, tiene que ser resultado de una creación libre y, en tal caso, no puede estar meramente dado, como la formalidad.

En el intento de salvar a la aprehensión primordial de realidad de la constructividad, Gracia margina de ella tanto la percepción como, más radicalmente, la sensación, que ahora no es más que una precepción simple. Y como identifica percepción y percepto, consigue expulsar definitivamente los contenidos de la aprehensión primordial. Pero, ¿es lo mismo percepción que percepto? En Inteligencia y logos podemos leer lo siguiente:

Aprehender 'esta' cosa es lo que constituye la aprehensión primordial de realidad, por ejemplo la percepción. Pues bien, el 'esto' de 'esta' cosa, desrrealizado, es el 'esto' de la cosa en cuanto mero término de percepción. $\mathrm{Al}$ 'esto' en cuanto mero término de la percepción es a lo que llamaré percepto. Reducir el contenido de la cosa real a percepto (1982, pp. 96-97).

A mi juicio, ello significa que percepción y percepto no coinciden: el percepto es percepción desrealizada. Sólo si es posible hacer referencia a la percepción desde la aprehensión primordial de realidad tienen sentido las páginas de Inteligencia y realidad en que Zubiri muestra cómo la formalidad modula el contenido en aprehensión primordial de realidad a través de sensaciones y percepciones:

la impresión sensible es una impresión que afecta al sentiente haciéndole presente lo que impresiona, esto es, una nota, en formalidad de independencia con un contenido propio tanto elemental (una sola nota) como complejo (una constelación de notas) (1980, p. 39).

Al respecto no podemos olvidar la conexión entre formalidad y formalización. La percepción en su forma más radical, es decir, prelógica, tiene que ver no con la 
desrealización del sería en la forma del percepto, sino con la formalización, con "el modo de habérselas del sentiente", es decir, con el término de una habitud; término que en su sentido más radical no apunta a la costumbre o hábito, sino a las estructuras talitativas del viviente, a la capacidad de formalización del cerebro del viviente en concreto. Es por ello que Zubiri puede distinguir esta formalización y percepción de aquello a que refiere la psicología de la Gestalt:

la formalización no concierte en primera línea a la configuración sino a la autonomización. La configuración es tan sólo el resultado de la autonomización. Sólo porque hay independencia puede haber y hay configuración. Formalización es la independencia, es lo constitutivo de la unidad del contenido en cuanto independiente, sea contenido elemental o sea una constelación (1980, p. 45).

A mi juicio, la autonomización está en la línea de la aprehensión primordial de realidad, mientras que la configuración está en la línea del percepto.

Las habitudes o modos de habérselas están arraigados en la aprehensión primordial de realidad. En su sentido más radical estas habitudes dependen de nuestra configuración biológica, en concreto, de la capacidad de formalización de nuestro cerebro. Aunque también son el resultado del precipitado de nuestra comprensión de lo real y por lo tanto de la actividad creativa de logos y razón. Esto significa que en la filosofía de Zubiri no tiene sentido el empeño fenomenológico de buscar un ámbito intelectivo inmediato, en el sentido de estar preñado de verdades absolutas.

A mi juicio, aprehensión compacta e inmediata no significa libre de construcción, sino asimilada al nivel de las habitudes. Cosa que, como muestran las costumbres, puede ocurrir a partir de construcciones profundamente arraigadas. Ello significa que quizás no tiene sentido seguir distinguiendo tajantemente entre una formalidad invariable y un contenido variable. Pero no porque, como afirma Víctor Tirado (2005 y 2008), sea posible hacer referencia a contenidos invariables, sino porque, al contrario, no hay nada invariable; no hay, no me cansaré de repetirlo, verdades absolutas en Zubiri.

Para algunos zubirianos esta interpretación acercará a Zubiri peligrosamente al relativismo y la hermenéutica. Pero en tanto que tal, esta crítica procede a una moralización del conocimiento. Antes es preciso atenerse a los hechos, y estos, a mi juicio, son nítidos en Zubiri. Nada es invariable y, por tanto, absoluto en Zubiri. Por supuesto nada talitativo, pero tampoco nada trascendental.

Claramente, el propio Zubiri ha introducido el dinamismo en el ámbito trascendental. En primer lugar, porque no podemos olvidar que lo trascendental es una función de lo talitativo, y, así, en Estructura dinámica de la realidad, Zubiri mostró que la realidad daba de sí no sólo talitavamente, sino también trascendentalmente.

Más acá de este dinamismo de lo trascendental en perspectiva intramundana, hay que preguntarse por su posibilidad en perspectiva noológica. Para ello introduz- 
cámonos brevemente en el trabajo de la razón y en la comprensión (cf. Barroso 2006 y 2009a).

Como es sabido, la razón constituye una marcha allende lo dado pero desde lo previamente dado en el logos: del campo al mundo; de lo real meramente dado y logificado, a "lo real en profundidad".

Es muy importante entender bien en qué consiste el apoyo de la razón en el logos. Los esbozos de la razón son construidos a partir de la misma realidad campal. El campo actúa como "sistema de referencia" para la intelección mensurada en profundidad.

La realidad campal inteligida es una realidad abierta que en esta apertura nos lanza allende la misma en búsqueda. Por ello esta realidad previa se constituye como fundamento de la intelección racional. Si el campo era actualizado en el logos para inteligir la cosa en su mero estar respectivo a través de la afirmación, este campo es ahora lo que nos lleva al allende, se constituye entonces no en medio, sino en realidad-fundamento o "principio" mensurante de la realidad allende. Si el logos intelige la realidad del campo como una luz que me permite alumbrar el estar de la cosa en su campalidad, la razón debe entenderse como una luminaria que mensura en su fundamento este estar. En la intelección de la realidad como principio "la razón es intelección en mensura principial de la realidad en profundidad" (1983, p. 45).

Como se puede observar, aquí las nociones de principio y fundamento tienen dos sentidos. Por un lado, el aquende se constituye en el fundamento para la marcha al allende: es el logos constituido como sistema de referencia para la razón. Por otro lado, el esbozo constituido a través del sistema de referencia nos presenta la realidad que debe entenderse como realidad-fundamento, la realidad principial, de la propia realidad campal: "lo que se busca en la intelección racional es cuál sea el fundamento de la cosa real campal" (1983, p. 186).

Cuando la razón fundamenta el campo de realidad, este puede sufrir modificaciones. Me he referido a tal posibilidad como a la refluencia de la razón sobre el logos. Pues bien, tal refluencia modificadora afecta no sólo a los contenidos del campo, sino también a las propias estructuras trascendentales. Cuando intelijo el campo de realidad no intelijo sólo determinadas cosas reales en su respectividad, sino también qué es aquello a lo que llamamos real. Es decir, los diversos "modos" de realidad, lo real considerado en su dimensión trascendental. Entonces, no sólo mensuro la realidad en profundidad a través de determinadas realidades del campo, sino también con un determinado metro de realidad. Este metro es precisamente el 'canon'; lo previamente inteligido en su forma y modo de realidad. Hay un ejemplo del propio Zubiri que puede servir para clarificar la cuestión:

En la intelección de las cosas reales del campo se había decantado en nuestra intelección no sólo la intelección de que las cosas reales son cuerpos, sino también y sobre todo la intelección de que ser real es ser 'cosa', en el sentido que tiene hoy el vocablo 
cuando se habla, por ejemplo, de 'cosismo'. Este era el metro de realidad: la marcha allende el campo se llevaba a cabo pensando que la realidad como mensurante es 'cosa'. Hizo falta una intelección mucho más difícil que la de la física cuántica para inteligir que lo real puede ser real y sin embargo no ser cosa. Ser, por ejemplo, persona (1983, p. 56).

No deja de ser curioso que esta idea de "metro" o canon estuviera ya presente en la fenomenología de Husserl. Efectivamente, para él, la reducción trascendental, por la que se prescinde de la realidad misma, permite que lo eidético se constituya en el metro de lo fáctico (Zubiri, 1963, p. 219). Y si el trabajo fenomenológico está bien hecho, si las intuiciones son recorridas en todas sus direcciones posibles, entonces se puede pensar, regulativamente, en un canon definitivo. Lo que significa que en Husserl no hay refluencia, sino que cuando, con la fenomenología, llegamos al canon, a la esencia de algo, hemos logrado algo absoluto. Zubiri, en referencia a Husserl, concluye: "Es el saber de la esencia lo que constituye el metro del saber de la realidad. Todo saber de hechos encuentra su posible justificación sólo en el saber absoluto de la esencia" (1963, p. 223).

Volviendo a la refluencia en Zubiri, en realidad, no es una actividad propia de la razón, sino más bien de la comprensión, último modo de aprehensión. Zubiri no entiende la aprehensión primordial, el logos y la razón como estructuras independientes, sino que constituyen tres momentos de un solo acto: la intelección sentiente. Es posible descomponer estos momentos para su análisis, pero la inteligencia es cualitativamente unitaria. Son tres modos de intelección, no tres planos; son modalidades de una misma función intelectiva.

¿Qué es entonces la intelección en su precisa unidad? Zubiri lo tiene claro: es comprensión o, más bien, aprehensión comprensiva (1983, p. 336). Distingue una primera actualización, la propia de la aprehensión primordial de realidad, de lo que llama una re-actualización de lo real, la que se produce en el logos y la razón. El acto unitario de la inteligencia es tal que la re-actualización envuelve la primera actualización. La primera actualización queda comprehendida por la segunda. En esta "comprehensión" queda incorporada a la cosa lo que realmente es.

Aunque en el análisis yo pueda distinguir la mera descripción lógica de la explicación racional, lo cierto es que en su unidad la intelección es aprehensión comprensiva, con lo que la refluencia de la marcha de razón sobre lo dado es inevitable. No hay un ámbito puro, a priori, $\mathrm{y}$, con ello, una vez más, no hay nada absoluto. Ni siquiera, como hemos visto, en lo que se refiere a lo trascendental. Sólo para una inteligencia concipiente puede pensarse lo trascendental como a priori. No así para una inteligencia sentiente (1980, p. 130), donde la transcendentalidad tiene que ser necesariamente dinámica. No sólo por el dinamismo de la propia realidad talitativa, sino por el dinamismo del mismo proceso intelectivo. Lo hemos visto en referencia a la superación del "cosismo" cuando se advierte, históricamente, que además de 
cosas en el mundo hay personas. Se descubre con ello una nueva forma de realidad, una nueva estructura trascendental. Obviamente, aquí lo trascendental ya no se mueve en el orden del a priori sino que tiene un carácter histórico.

Habría que preguntarse si la refluencia afecta a otras estructuras trascendentales más radicales que la que constituyen las formas y modos de realidad. Se trata sin duda de un trabajo complejo que exige múltiples mediaciones, como por ejemplo la de la antropología cultural. Aquí no puedo más que constatar que en principio no encuentro argumentos para entender que el ámbito de lo trascendental queda al margen de esta refluencia y que por lo tanto tampoco a él se le puede atribuir un carácter absoluto al margen de toda construcción.

Lo más radical que se puede decir de la realidad en un sentido trascendental es que es "de suyo". Sólo basándonos en ello podemos describir adecuadamente en qué consisten otras dimensiones de esta trascendentalidad, como, por ejemplo, la fuerza y el poder con que lo real es sentido o, yendo más allá, la verdad, el bien o la belleza. Al respecto he intentado mostrar que el inteleccionismo de Zubiri hace aguas en múltiples momentos de su obra (cf. Barroso, 2008 y 2010), o dicho de otra forma, que la manera zubiriana de entender el ámbito de lo transcendental depende de una concreta disposición afectiva (en el sentido de la Befindlichkeit heideggeriana): la temperie.

\section{Conclusión}

¿Puede entenderse la descripción de hechos en que consiste Inteligencia sentiente como una descripción de carácter fenomenológico? Si consideramos la fenomenología como una idea de filosofía que ha encontrado un objeto y un ámbito propio del filosofar más allá del carácter ancillar respecto a otras formas de saber, quizás podríamos responder afirmativamente. Ahora bien, hay que matizar el sentido fenomenológico de tal posibilidad en Zubiri en varias direcciones.

Hay sentidos bastante estudiados de esta matización. Así, por ejemplo, es claro que tal fenomenología zubiriana se movería al margen de la fenomenología eidética y trascendental de Husserl, o de la fenomenología hermenéutica de Heidegger, al fundar la cosa-sentido en la cosa-realidad (cf. Cerezo, 1995). Pero yo aquí me he referido a otra diferencia respecto a la fenomenología de Husserl: la de Zubiri no se constituye como un tipo de saber absoluto.

Obviamente, aun el carácter absoluto del saber fenomenológico para Husserl, este no pretendía que su descripción fenomenológica tuviera que ser necesariamente definitiva. Su propia trayectoria biográfica le mostraba que la fenomenología está sometida a una continua depuración conceptual, porque las intenciones nunca agotarán su objeto de estudio, en tanto que siempre es posible abrir y descubrir nuevos 
sentidos. Con todas las matizaciones que en Zubiri implica la situación de la aprehensión primordial de realidad como algo previo al logos, es fácil observar que, por lo visto en el presente ensayo, Zubiri participa de esta idea depurativa de la fenomenología.

Tampoco tendría problemas Zubiri en aceptar que el trabajo fenomenológico está abierto a una revisión continua a través de los "cambios de validez" (Husserl 1976, pp. 163-167) que presuponen la medida intersubjetiva de las descripciones. Las descripciones no permiten la corroboración más que viviéndolas en la propia carne, y tal vivencia le da un carácter propio a lo que aquí se puede entender por discipulado fenomenológico:

No será la comunicación de proposiciones evidentes, sino una participación en el esfuerzo de conquistar por sí propio las más estrictas evidencias. Es posible que en su ejecución se separen hondamente los discípulos (Zubiri 2002, p 187).

Pero Zubiri va mucho más lejos. Aún cuando ha separado analíticamente aprehensión primordial, logos y razón, lo cierto es que en realidad no constituyen más que momentos de una intelección sentiente única. Con lo que nos encontramos habitualmente es con aprehensiones comprensivas. Es decir, aprehensiones refluidas por la comprensión y por lo tanto ellas mismas sometidas a variaciones. Es decir, las revisiones descriptivas no dependen sólo del empeño depurativo o los cambios de validación intersubjetiva, sino, también y más radicalmente, de la verificación y el cumplimiento propios de la verdad racional. Y si esto es así, hemos de entender que la misma descripción fenomenológica se ve afectada por la historicidad propia de la razón. Obviamente, lo histórico y lo absoluto no son compatibles.

Husserl pretendió mostrar la conexión de la ciencia y el mundo de la vida: cómo la ciencia surge del mismo mundo de vida. Hizo paréntesis del ámbito científico y se preguntó qué era el mundo de vida, para ver cómo de él surge la ciencia. Por ello para Husserl la fenomenología es ciencia estricta y rigurosa, con el modelo matemático en mente. Husserl participa de la idea cartesiana de que la filosofía tiene que superar la discusión sin fin, y para ello entiende que es posible decidir las cuestiones apelando a los fenómenos, a las cosas mismas. Su filosofía, desde aquí, pretende tener validez absoluta. Como el propio Zubiri recoge en sus Cinco lecciones de filosofia: "la filosofía, nos dice Husserl, es la indeclinable aspiración de la humanidad a un conocimiento puro y absoluto" (1963, p. 212). Husserl cree haber encontrado una ciencia absoluta en la fenomenología, cuyo objeto está al alcance de todos y sobre el que se pueden tener conocimientos justificados, plenamente evidentes, ya que fenómeno no es más que lo manifiesto en cuanto manifiesto.

A través de la intuición, aquella intención en la que el objeto está dado inmediatamente a la conciencia, llegamos a algo absoluto. Y a través de la "repleción" (como traduce Zubiri el Erfüllung de Husserl), podemos hacer que intenciones, en 
principio no intuitivas, alcancen la evidencia. Con lo que conseguimos llevar el carácter absoluto de este saber más allá de aquello de lo que tenemos intuiciones inmediatas. Tener evidencia de algo es alcanzar algo absoluto sobre ese algo. La ciencia estricta y absoluta está servida: sólo tenemos que seguir, a partir de la intuición de los objetos, sus posibles manifestaciones, prefijadas en lo dado. Es decir, en Husserl el horizonte es algo prefijado, sólo que los caminos han de ser recorridos activamente; aquí está la labor de la filosofía: penoso esfuerzo por alcanzar evidencias absolutas y cada vez más adecuadas.

Para Zubiri, la conexión entre ámbito científico y filosófico es más profunda, ya que aquel paréntesis del mundo científico no puede hacerse en realidad más que de una forma tremendamente superficial. La descripción de un hecho fenomenológico no es más que una descripción del campo a partir de razones fuertemente asentadas, refluidas sobre lo previamente inteligido, lo que hace que tanto las intuiciones como el horizonte que prefiguran sean dependientes de la marcha histórica de la razón y, sobre todo, de esa experiencia racional que llamamos ciencia.

Ello no significa que la filosofía haya caído nuevamente en saber genitivo, es decir, en una forma de saber sólo posible como reflexión a partir de otros saberes de los que tomaría su propio objeto. Ignacio Ellacuría, en un ensayo dedicado a la antropología en Zubiri, afirmó que

la filosofía en general y la Antropología filosófica en particular no trabajan en el fondo sobre los datos que en cada momento les dan las ciencias, sino sobre la realidad que las ciencias les han hecho accesible con mayor o menor rigor crítico. Las ciencias positivas -también otras formas de comportamiento humano, como la propia experiencia personal, la actividad artística, la vida cotidiana, la praxis social, etc.--, nos hacen presente, realmente de alguna forma, la realidad, y este hacernos presente realmente la realidad no es algo previo, sino momento constitutivo del filosofar mismo, pues sin él la actividad filosófica sería vacía (1976, p. 67).

En esta realidad continuamente explorada por la razón, la filosofía va recomponiendo su análisis del logos.

Además, no es sólo que el objeto de la filosofía sea distinto del objeto de la razón, sino que la tarea filosófica adquiere en este planteamiento una importancia de primer orden. Ya que si bien en cierto que las verdades racionales están continuamente refundando el campo y, por lo tanto, transformándolo, no es menos cierto que el campo, como sistema de referencia de la razón, desempeña también un papel fundamental respecto a dichas verdades. Por ello las descripciones fenomenológicas constituyen una condición de posibilidad del saber racional. Su ausencia puede llevar a errores racionales garrafales.

Desde una tradición distinta a la fenomenológica, Deleuze y Guattari han entendido que mientras que la ciencia establece "functores", la filosofía crea conceptos. 
Con ello también han encontrado una idea de filosofía que les permite un espacio propio más allá de toda servidumbre. Pero al mismo tiempo afirman que

esta misma oposición entre las multiplicidades científicas y filosóficas, discursivas e intuitivas, extensionales e intensivas, también es acta para enjuiciar la correspondencia entre la ciencia y la filosofía, su colaboración eventual, su inspiración mutua (1993, p. 128).

Considero que comprender bien a Zubiri exigirá, en el futuro, pensar su filosofía desde parámetros del pensamiento de la diferencia. Sin duda las distancias son enormes en muchos puntos, pero hay una similitud especialmente interesante entre el proceder de Zubiri y el de Deleuze.

El hecho de que las descripciones del logos constituyan un referente ineludible del trabajo racional y de que, al mismo, tiempo, la razón refluya sobre el propio logos, nos hace caer en la cuenta del carácter circular del conocimiento. Las comparaciones con el círculo hermenéutico resultan aquí inevitables, aunque hay una diferencia de peso que salta enseguida a la vista. En la hermenéutica, y por lo tanto en su presunto círculo, la fuerza ha sido radicalmente desterrada o, mejor, reducida a sentido. En esto acusa el pensar de Heidegger, para el que la fuerza aparece como enemiga del acontecer en su propiedad, es decir, en tanto que apertura de sentido. Creo que es aquí donde hay que cifrar la crítica de Zubiri a la hermenéutica; su afirmación de que la cosa-real fundamenta a la cosa-sentido. Es también la razón por la cual Zubiri se opone a la equiparación, por parte de la hermenéutica ontológica, de comprensión e intelección.

Al respecto, es claro que la descripción zubiriana del momento radical de la intelección, la aprehensión primordial de realidad, permite superar el olvido hermenéutico de la fuerza. Para Zubiri la realidad está presente físicamente en la intelección, actualizada en su fuerza propia. Pues bien, partiendo de Nietzsche, Deleuze ha intentado, frente a la hermenéutica, recuperar la fuerza para la filosofía (cf. Sáez, 2009, pp. 209 y ss).

Entrar en esta interesante coincidencia entre Zubiri y Deleuze nos llevaría más allá de los propósitos del presente trabajo. Lo importante es mostrar que el círculo de fundamentación entre logos y razón en Zubiri no coincide con el círculo hermenéutico. El saber nunca perderá este carácter circular, aunque todos esperamos que el carácter impelente de la realidad en su fuerza haga que el círculo aumente continuamente su radio y que, con ello, nuestra comprensión de lo real sea cada vez más elevada. El carácter circular del saber no es incompatible con sus pretensiones de progreso y universalización... al menos, no lo es en la filosofía del propio Zubiri, que aún aceptando la dimensión histórica de toda verdad racional, nunca negó la posibilidad del progreso en el saber. 
Me preguntaba en el subtítulo de este trabajo en qué sentido puede entenderse que la filosofía de Zubiri es una fenomenología. Obviamente, no lo es en el sentido husserliano de un saber absoluto. Pero la hermenéutica, sin salir de los márgenes de la corriente fenomenológica, ya negó la posibilidad de un saber tal. Entonces, ¿por qué esta pregunta? En realidad, el problema no está en la negación de tal saber absoluto, sino en la forma en que Zubiri ha llegado a ella: a través de un intento de conjugación de los ámbitos de la facticidad y la esencialidad. Conjugación que le llevaba a situarse, más allá de la esfera del sentido, en la realidad. La cuestión es, como ha visto Rodríguez (2009), si este intento de rebasamiento de la esfera del sentido no es, a su vez, un rebasamiento de los márgenes de la misma fenomenología. Y a poco que se observe la estrategia que Zubiri siguió en Sobre la esencia, se verá que la conjugación que propone de esencialidad y facticidad es totalmente externa al análisis fenomenológico. La crítica, tanto a Husserl como a Heidegger, es injusta en tanto que salta sobre los límites de la propia fenomenología; es una crítica, a todas luces, metafísica (aún cuando se trate de una metafísica intramundana). Ni la facticidad ni la esencialidad que permiten la conjugación son, en realidad, de carácter fenomenológico. De hecho, hemos visto que aunque Zubiri distingue entre esencia denominativa y esencia en sentido riguroso, y mientras que critica a Husserl desde la segunda noción, sólo la primera es de carácter fenomenológico. Lo que significa que la crítica de Zubiri a Husserl -o, dicho de forma más adecuada, a la imagen de Husserl que él mismo había construido- es de carácter metafísico.

Zubiri debió darse cuenta de este problema y por ello emprendió tras Sobre la esencia la tarea de fundar fenomenológicamente el sentido en la realidad. Tarea que culminó en la publicación de Inteligencia sentiente. Pero si tenemos en cuenta que esta fundamentación aparece originalmente como una tesis metafísica -y no fenomenológica- y que para Zubiri la descripción de hechos está refluida por nuestros logros racionales -científicos y metafísicos-, es problemático referirse a ella como descripción fenomenológica. Es decir, es cuestionable que la fundamentación del sentido en la realidad se mantenga dentro de los márgenes de la tradición fenomenológica.

El zubirismo, en su intento de evitar las lecturas neoescolásticas de Zubiri, ha tendido a separar en su filosofía lo metafísico y lo noológico, y a despreciar lo primero. Quizás ha llegado el momento de reivindicar, sin complejos, aquello a lo que Zubiri siempre concedió la máxima dignidad: la Metafísica.

\section{Referencias bibliográficas}

BAÑón, J. (1999), Metafisica y noología en Zubiri, Universidad Pontificia de Salamanca. 
BARroso, O. (2006) "La crítica de Zubiri a la hermenéutica heideggeriana desde la descripción del proceso intelectivo", Philosophica, 29, pp. 93-123.

Barroso, O. (2009a) "El fundamento en Zubiri. Aportaciones de su filosofía al debate antropológico entre relativismo y universalismo", Daimon, 48, pp. 117 135.

Barroso, O. (2009b) "Nihilismo, ontología y disposiciones afectivas", en L. Saez y otros (eds.), Nihilismo y mundo actual, Universidad de Granada, pp. 93-114.

Barroso, O. (2010) "Zubiri, ¿antídoto contra el nihilismo o disimulo de la melancolía?”, en P. Peñalver y J.L. Villacañas (eds.), Razón de Occidente. Textos reunidos para un homenaje al profesor Pedro Cerezo Galán, Madrid, Biblioteca Nueva, pp. 387-414.

CEREzo, P. (1995) “Del sentido a la realidad. El giro metafísico en X. Zubiri”, en D. Gracia (ed.), Del sentido a la realidad. Estudios sobre la Filosofia de X. Zubiri, Madrid, Trotta, pp. 221-254.

Deleuze, G. y Guattari, F. (1993), ¿Qué es filosofía?, Barcelona, Anagrama.

EllaCURÍA, I. (1976) "Introducción a la antropología en Zubiri”, Realitas. Trabajos del Seminario Xavier Zubiri, vol. 2.

GARCíA-BARÓ, M. (2012), Sentir y pensar la vida, Madrid, Trotta.

Gracia, D. (1986), Voluntad de verdad. Para leer a Zubiri, Barcelona, Labor.

GRACIA, D. (2008) "El problema del fundamento", en J.A. Nicolás y R. Espinoza (eds.), Zubiri ante Heidegger, Barcelona, Herder, pp. 33-79.

EspinozA, R. (2008), “Heidegger y Zubiri. Después del ser y la realidad: el problema del Ereignis”, en J.A. Nicolás y R. Espinoza (eds.), Zubiri ante Heidegger, Barcelona, Herder, pp. 197-250.

GonzÁlez, A. (2004), "Ereignis y actualidad”, en D. Gracia (ed.), Desde Zubiri, Granada, Comares, pp. 103-192.

Husserl, E. (1976), Die Krisis der europäischen Wissenschaften und die transzendentale Phänomenologie, Husserliana, vol. 6, La Haya, Martinus Nijhoff.

Pintor-Ramos, A. (1994), Realidad y verdad. Las bases de la filosofia de Zubiri, Universidad Pontificia de Salamanca.

Martínez Castro, R. (2004), "La metafísica de Zubiri”, en J. A. Nicolás y O. Barroso, Balance y perspectivas de la filosofía de Zubiri, Granada, Comares, pp. 149-164.

RodríGueZ, R. (2009), "Impresión de realidad y comprensión de sentido", en A. Pintor-Ramos, Zubiri desde el siglo XXI, Publicaciones de la Universidad Pontificia de Salamanca, pp. 261-280.

SÁez, L. (2009), Ser errático. Una ontología crítica de la sociedad, Madrid, Trotta. Serrano, A. (2010), "Zubiri ante la idea de fenómeno", en I. García (ed.), De nobis ipsis silemus. Homenaje al Profesor Juan Miguel Palacios, Madrid, Encuentro, pp. 481-499. 
Tirado, V. (2005), "Husserl et Zubiri. Six études pour une controverse", en Ouverture Philosophique, París, L'Harmattan.

Tirado, V. (2008), "Fenomenología del logos. Zubiri y Heidegger", en J.A. Nicolás

y R. Espinoza (eds.), Zubiri ante Heidegger, Barcelona, Herder, pp. 251-284.

Zubiri, X. (1944), Naturaleza. Historia. Dios, Madrid, Alianza, 19879.

ZuBIRI, X. (1962), Sobre la esencia, Madrid, Alianza, $1985^{5}$.

ZuBIRI, X. (1963), Cinco lecciones de filosofía, Madrid, Alianza, 1980³.

ZUBIRI, X. (1980), Inteligencia sentiente. Inteligencia y realidad, Madrid, Alianza.

ZuBIRI, X. (1982), Inteligencia y logos, Madrid, Alianza.

ZuBIRI, X. (1983), Inteligencia y razón, Madrid, Alianza.

ZuBIRI, X. (1999): Primeros escritos (1921-1926), Madrid, Alianza.

Zubiri, X. (2001), Sobre la realidad, Madrid, Alianza.

Zubiri, X. (2002), Sobre el problema de la filosofía y otros escritos (1932-1944), Madrid, Alianza.

Óscar Barroso Fernández

Departamento de Filosofía II

Facultad de Filosofía y Letras

Universidad de Granada

obarroso@ugr.es 